\title{
A Study of Effect of Binding sites on Polyelectrolyte Induced Metachromasy
}

\author{
Nandini R* \\ *Department of Chemistry MITE, Moodbidri \\ *Corresponding author: E-Mail: nandinifalnir@ yahoo.com, Telephone: 9964412316 \\ ABSTRACT
}

The interaction of a cationic dye namely, Methylene blue (MB) with anionic polyelectrolytes, namely, sodium carboxy methylcellulose ( $\mathrm{NaCMC}$ ) and Sodium heparinate has been investigated by spectrophotometric technique. The polymers induced metachromasy in the dye resulting in the shift of absorption maxima of the dye towards shorter wavelengths. The stability of the complex formed between MB and NaCMC was found to be lesser than that formed between MB and NaHep. This fact was further confirmed by reversal studies using alcohols, urea and electrolytes. The interaction parameters revealed strong binding between MB-NaHep complexes. The number of binding sites was found to affect metachromatic shift and other interaction parameters. Among the two polyelectrolytes, NaHep has a greater number of binding sites, hence dye aggregation was found to be greater in MB-NaHep complex than in MB-NaCMC complex.

KEY WORDS: Metachromasy, Methyleneblue, Anionic Polyelectrolytes, Aggregation, Binding Sites.

\section{INTRODUCTION}

The term metachromasy refers to the change in the visible absorption spectra of the dye, on interaction with a polymer/polyelectrolyte. It occurs due to aggregation of dye molecules on the polymer backbone (Chakraborty, 1997; Mitra, 2006). Here we briefly report the interaction of Methylene blue with various polyelectrolytes. The interaction of Methylene blue with sodium alginate has been reported in the literature (Seely, 1983). Poly (potassium styrene sulfonate) and poly (sodium 4-vinylphenylsulphate) interacted with Methylene Blue to form aggregated polymers (Shirai, 1977). The effect of alkali metal chlorides and 1-substituted 3carbomylpyridinium bromides on the metachromatic behavior of methylene blue induced by poly (potassium styrene sulfonate) and poly (potassium vinyl sulfate) was investigated spectrophotometrically (Shirai, 1977). The structural effect of polyanion on the metachromatic behavior of methylene blue was investigated spectrophotometrically using poly (sodium acrylate), conventional poly (sodium methacrylicacid), isotactic poly (sodium methacrylate) and the copolymer poly (sodium maleate-covinyl alcohol). The metachromatic behavior was followed by the changes in the molar absorption coefficient of methylene blue and in the wavelength of the metachromatic band. (Shirai, 1977). The effect of polyanion on the formation of mixed dimers of methylene blue and trypaflavine, Methyelne blue and Phenosafranin and Methylene blue and Pyronine $G$ was investigated spectrophotometrically (Shirai,1978). The effect of polyanion poly (potassium vinylsulfate) poly (sodium acrylate) on the alkaline fading reaction of Methylene blue was investigated (Shirai, 1978). The interaction of methylene blue with poly (vinyl alcohol) has been studied (Otsuki, 1993). The interaction of Methylene Blue with amorphous potassium chondroitin sulphate and crystalline chondroitin sulphate were studied by spectrophotometric method (Ghosh, 1981)Hence the main objective underlying the current study is to investigate the extent to which the number of binding sites affects the metachromatic behavior The reversal of metachromasy on addition of alcohols, urea, $\mathrm{NaCl}, \mathrm{KCl}$ and oppositely charged surfactants, temperature and the thermodynamic parameters of interaction will also be reported.

\section{MATERIALS AND METHODS}

Methylene Blue (Acros Media) were used without further purification. Methanol, Ethanol and Propanol were obtained from (Merck, India) and were distilled before use. Sodiumlaurylsulphate and Sodiumdodecyl benzene sulphonate (Lobachemie, India) were used as received. Sodiumcarboxymethyl cellulose was obtained from (BDH, UK) and Sodium heparinate was obtained from (Lobachemie, India). The spectral studies were carried out using Shimadzu UV-2550 spectrophotometer.

Determination of stoichiometry and interaction parameters of Polymer-dye complexes: The equivalent weight of NaCMC sample was determined using standard methods and it was found to be $222 \mathrm{~g}$. The equivalent weight of NaHep sample was determined using conductometric titration method and it was found to be 178g. (Casu, 1975; Ramus, 1977).

Preparation of dye \& polymer solutions: The stock solutions of the various dyes were made in $100 \mathrm{ml}$ volumetric flasks using distilled water. The stock solutions of polymers of concentration $1 \times 10^{-2} \mathrm{M}$ was made in $100 \mathrm{ml}$ volumetric flask considering the equivalent weights of the polymer. 


\section{Sun International Journal of Engineering and Basic Sciences}

Preparation of electrolyte and surfactant solutions: The stock solutions of concentration $0.1 \mathrm{M}$ were made in $100 \mathrm{ml}$ volumetric flasks using distilled water. Appropriate amount of these solutions were used to obtain concentrations in the range $0.01 \mathrm{M}-1 \times 10^{-8} \mathrm{M}$ in various experiments.

Preparation of urea solution: The stock solution of concentration 9M was made in $100 \mathrm{ml}$ volumetric flasks using distilled water. Appropriate amount of this stock solution were used to obtain concentrations in the range $1-8 \mathrm{M}$ in various experiments.

Preparation of polymer-dye solutions for studying reversal of metachromasy: For the study of reversal of metachromasy, solutions containing polymer \& dye in a fixed ratio, which exhibited highest shift, were made. Generally $0.5 \mathrm{ml}$ of $1 \times 10^{-3} \mathrm{M}$ dye solution and appropriate amount of polymer solution $\left(0.0-0.9 \mathrm{ml}\right.$ of $\left.1 \times 10^{-2} \mathrm{M}\right)$ solution were mixed in $10 \mathrm{ml}$ volumetric flask and appropriate amounts of alcohols, $\mathrm{NaCl}(0.1 \mathrm{M})$, urea $(9 \mathrm{M})$, or surfactant $(0.1 \mathrm{M})$ were added and the solution was made up to $10 \mathrm{ml}$ with distilled water.

Determination of thermodynamic parameters: The thermodynamic parameters of interaction are determined as follows: Solutions containing different amounts of polymer samples (1, 2, 4 and $\left.5 \mathrm{ml} \mathrm{x} 10^{-3} \mathrm{M}\right)$ and fixed amount of dye solution $\left(0.5 \mathrm{ml}, 1 \times 10^{-3} \mathrm{M}\right)$ were made up to $10 \mathrm{ml}$ in different volumetric flasks and the solutions were equilibrated and the readings were measured at 4 different temperatures, $36^{\circ} \mathrm{C}, 42^{\circ} \mathrm{C}, 48^{\circ} \mathrm{C}$ and $54^{\circ} \mathrm{C}$. The absorbances were measured at both monomeric and metachromatic band. Absorbance results were treated using Rose-Drago Equation:

$$
\mathrm{C}_{\mathrm{D}} \cdot \mathrm{Cs} /\left(\mathrm{A}-\mathrm{A}_{0}\right)=1 /\left(\mathrm{K}_{\mathrm{c}} \mathrm{L}\left(\varepsilon_{\mathrm{DS}}-\varepsilon_{\mathrm{D}}\right)\right)+\mathrm{Cs} /\left(\mathrm{L}\left(\varepsilon_{\mathrm{DS}^{-}} \varepsilon_{\mathrm{D}}\right)\right)
$$

Where, $C_{D}$ is the the initial molar concentration of the dye; $C s$ is the molar concentration of the polymer; A is the absorbance of the polymer-dye complex at the metachromatic band; Ao is the absorbance of the pure dye at the metachromatic band; $\varepsilon_{D S}$ is the molar extinction coefficient of the polymer-dye complex; $\varepsilon_{D}$ is the molar extinction coefficient of the dye.

At each temperature the value of $\mathrm{K}_{\mathrm{c}}$ was obtained from the slope and intercept of the plot of $\mathrm{C}_{\mathrm{D}} \mathrm{C}_{\mathrm{S}} / \mathrm{A}-\mathrm{A}_{0}$ against $\mathrm{C}_{\mathrm{S}}$ at each temperature studied.

$$
\mathrm{K}_{\mathrm{c}}=\text { Slope/(Intercept). }
$$

The free energy change $(\Delta \mathrm{G})$, enthalpy change $(\Delta \mathrm{H})$ and entropy change $(\Delta \mathrm{S})$ associated with complex formation between dye and the polymer were calculated using the standard expressions, $\Delta \mathrm{G}=-\mathrm{RT} \operatorname{lnK}_{\mathrm{c}}$; $\operatorname{lnKc}=-\Delta \mathrm{H} /(\mathrm{RT})+\mathrm{C} ;$ and $\Delta \mathrm{G}=\Delta \mathrm{H}-\mathrm{T} \Delta \mathrm{S}$.

\section{RESULTSAND DISCUSSION}

The spectra of pure Methylene blue (MB) dye, shows an absorption maxima at $628 \mathrm{~nm}$. When Sodium carboxy methylcellulose solution is added to the above dye solutions, the spectra shows a blue shift, which occurs at555 nm in case MB-NaCMC complex and at 528nm in case of MB-NaHep complex. The reason for the blue shift being, the aggregation of dye molecules on the polymer backbone as reported by (Basu, 1982; Pal, 1961). The results are shown in Fig.1 \& Fig. 2

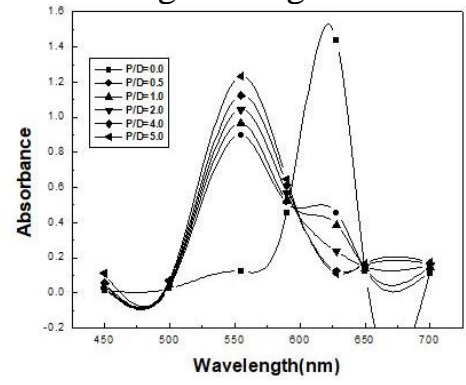

Figure.1. Absorption spectra of MB-NaCMC

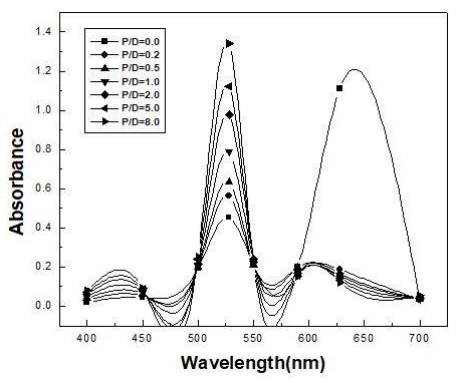

Figure.2. Absorption spectra of MB-NaHep

Stoichiometry: The stoichiometry of MB-NaCMC \& MB-NaHep complex were determined as mentioned earlier in the experimental section and were found to be 1:1 and 2:1 respectively. A 2:1 stoichiometry suggests that dye binding occurs at alternative site of the polyelectrolyte while in case of 1:1 stoichiometry binding of the dye molecule occurs at adjacent anionic sites resulting in a card pack stacking of the dye molecules on the polymer backbone. These results are in good agreement with those already reported in literature for binding of Pinacyanol chloride with Poly (Meth acrylic acid) and Poly (Styrenesulfonate) systems by (Pal, 1979; 1980). Fig.3, shows the stoichiometry of the complexes. 
Sun International Journal of Engineering and Basic Sciences

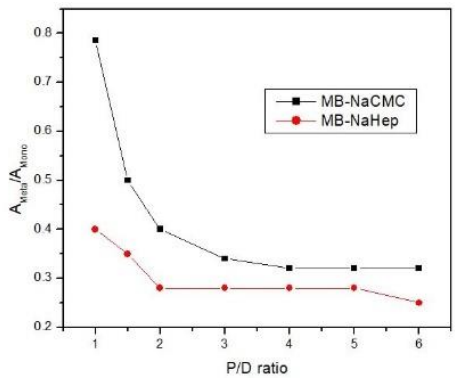

Figure.3. Stoichiometry of Polymer-dye complexes

Effect of alcohols and urea on metachromasy: When alcohols such as Methanol, ethanol and 2-propanol were added to case of MB-NaCMC \& MB-NaHep complexes the metachromatic bands disappeared and the bands of the pure dyes reappeared. This is due to breaking of the polymer-dye complex and release of pure dye in the solution. These observations indicated the involvement of hydrophobic forces in the polymer-dye complex formation. Further it was also observed that as the hydrophobic chain length of alcohols increases the reversal becomes quicker. Our observations matches well with that reported in the literature. (Frank, 1961). The results are shown in Fig.4, Fig.5 \& Fig. 6 respectively.

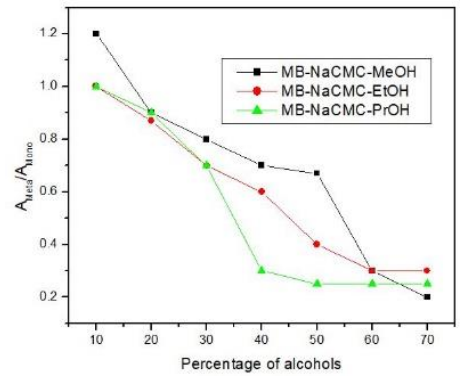

Figure.4. Effect of alcohols on MBNaCMC system

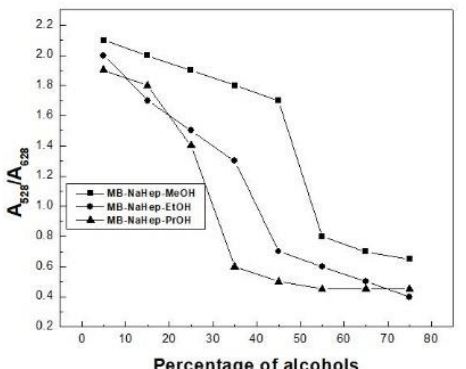

Figure.5. Effect of alcohols on MB-NaHepsystem

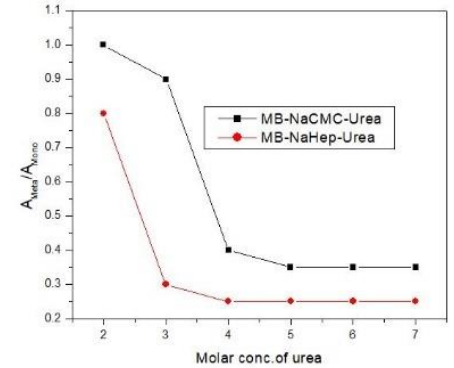

Figure.6. Effect of urea on Polymer-dye systems

Effect of electrolytes: On adding the electrolytes $\mathrm{NaCl} / \mathrm{KCl}$ to the MB-NaCMC \& MB-NaHep complexes, the metachromatic band disappears and the original monomeric band reappears. The reason behind this being, the change in conformation of polymer from extended conformation before adding dye to compact coil conformation on binding with the dye. The reversal of metachromasy on addition of electrolytes indicates the involvement of electrostatic forces in polymer-dye interaction. These observations have been supported by literature reports of (Tan \& Schneider, 1975). The results are depicted in Fig.7 \& Fig. 8.

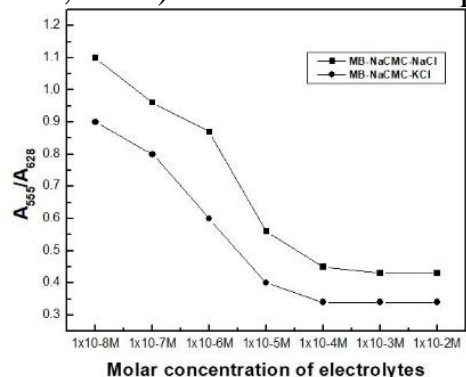

Figure.7. Effect of electrolytes on MB-NaCMC system

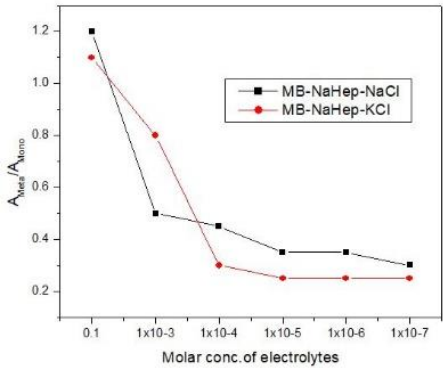

Figure.8. Effect of electrolytes MB-NaHep system

Effect of surfactants: On adding surfactants to MB-NaCMC \& MB-NaHep complexes the polymer interacts with the oppositely charged surfactant molecules and releases the free dye into the solution, as a result the monomeric band of the dye reappears. This is due to the interaction between anionic site of the polymer with the surfactant thereby releasing the free dye into the solution, which indirectly indicates the involvement of electrostatic forces involved in polymer-dye binding. Moreover as the chain length of the surfactant increases, the reversal became quicker, thus indicating that hydrophobic forces also play a vital role in polymer-surfactant interaction. These facts were also supported by reports from (Konradi \& Ruhe, 2005; Villeti, 2004; Romani, 2005). The Fig.9 \& Fig.10 shows the effect of surfactants. 
Sun International Journal of Engineering and Basic Sciences
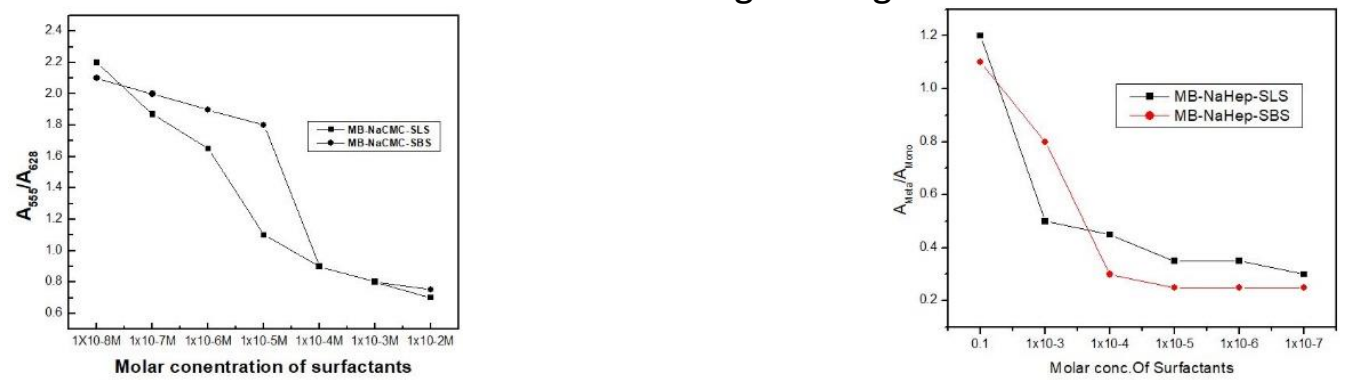

Figure.9. Effect of surfactants MB-NaCMC system Figure.10. Effect of surfactants MB-NaHep system Determination of interaction parameters: The interaction between the polymer-dye were studied at various temperatures ranging from $309 \mathrm{~K}-327 \mathrm{~K}$ and the interaction constant $\mathrm{K}_{\epsilon}$ and other thermodynamic parameters namely, $\Delta \mathrm{G}, \Delta \mathrm{H} \& \Delta \mathrm{S}$ were evaluated as mentioned earlier. The negative value of $\Delta \mathrm{H}$ indicates the exothermic nature of polymer-dye interaction. Also the negative value of $\Delta \mathrm{S}$ indicates an orderly arrangement of ions. The results are given in Table.1.

Table.1. Thermodynamic parameters of Polymer-dye systems

\begin{tabular}{|c|c|c|c|c|c|}
\hline System & $\operatorname{Temp}(K)$ & $\mathrm{K}_{\mathrm{C}}\left(\mathrm{dm}^{3} \mathrm{~mol}^{-1}\right)$ & $\Delta \mathrm{G}\left(\mathrm{kJ} . \mathrm{mol}^{-1}\right)$ & $\Delta \mathbf{H}\left(\mathrm{kJ} . \mathrm{mol}^{-1}\right)$ & $\Delta S\left(J\right.$. mol $\left.^{-1} \mathrm{~K}-1\right)$ \\
\hline \multirow[t]{4}{*}{ MB-NaCMC } & 309 & 6218 & -22.4 & & \\
\hline & 315 & 5415 & -22.6 & -23.5 & -33.3 \\
\hline & 321 & 4321 & -22.3 & & \\
\hline & 327 & 3785 & -23.7 & & \\
\hline \multirow[t]{4}{*}{ MB-NaHep } & 309 & 7315 & -22.8 & -20.2 & -38.3 \\
\hline & 315 & 6512 & -23.0 & & \\
\hline & 321 & 5423 & -23.5 & & \\
\hline & 327 & 4751 & -23.8 & & \\
\hline
\end{tabular}

Effect of binding sites: The structures of sodium carboxymethyl cellulose and Sodium heparinate are given below:

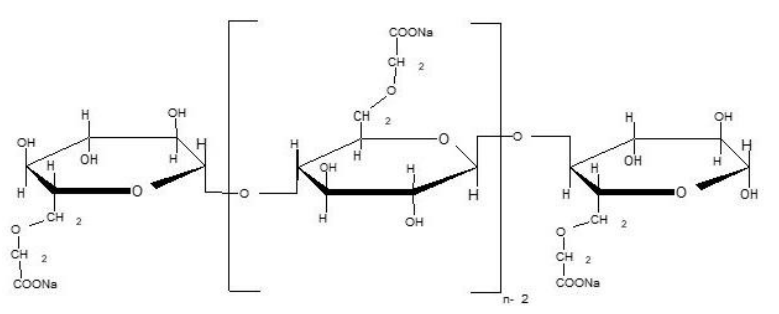

Figure.11. Structure of NaCMC

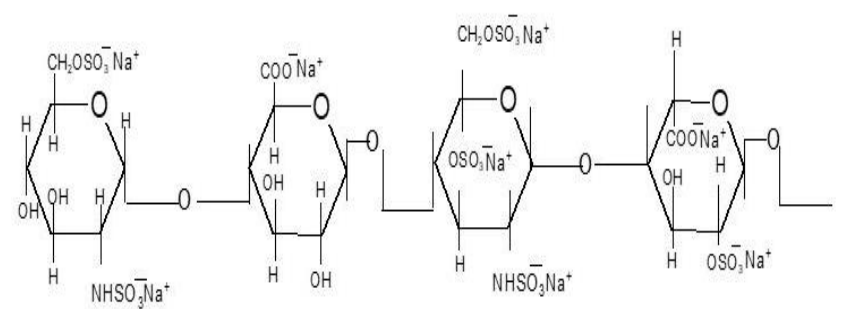

Figure.12. Structure of NaHep

On comparing the above structures, it is evident that for heparin there are two binding sites, namely carboxylate and sulphate groups, whilst sodium carboxy methyl cellulose contains only carboxylate groups. Hence, binding between heparin Methylene Blue and is stronger than in the case of Methylene Blue and sodium carboxy methylcellulose. These facts are further confirmed by the interactions constants and other interaction parameters.

\section{CONCLUSIONS}

From the present investigation it can be concluded that both the anionic polyelectrolytes, namely, NaCMC and NaHep induced metachromasy in the dye Methylene Blue. The extent of metachromasy induced by in Sodium heparinate was greater than that by Sodium carboxy methylcellulose. This is evident in the extent of blue shift which is $100 \mathrm{~nm}$ in case of MB-NaHep complex and $73 \mathrm{~nm}$ in case of MB-NaCMC complex. The above fact is also confirmed by the interaction constants which are higher for MB-NaHep complex than that for MB-NaCMC complex. Further it was also found that the number of binding sites also influences metachromasy.

\section{REFERENCES}

Basu S, Gupta AK, Rohatgi-Mukherjee KK, Concentration depolarization, energy-transfer and kinetics of concentration quenching of fluorescence of anthracene sulfonates, J. Indian Chem. Soc., 59, 1982, 578-582.

Casu B \& Gennaro U, A conductimetric method for the determination of sulfate and carboxyl groups in heparin and other mucopolysaccharides, Carbohydrate Research, 39, 1975, 168-176.

Chakraborty A.K, Panda A.K, Studies on the interaction of bacterial lipopolysaccharide with cationic dyes by absorbance and fluorescence spectroscopy, J. Photochrem. PhotobiolA. Chem, 111, 1997, 157-162.

Frank HS, Quist AS, Pauling's Model and the Thermodynamic Properties of Water, J. Chem Phys., 1961, 34, 604. 


\section{Sun International Journal of Engineering and Basic Sciences}

Ghosh S, Moulik S.P, Spectrophotometric investigation on the interaction of acridine orange with methylene I blue, phenosafranine, and disulphine blue in aqueous medium, Can. J. Chem., 59, 1981, 2449-2456.

Konradi R, Ruhe J, Binding of Oppositely Charged Surfactants to Poly (methacrylic acid) Brushes, Macromolecules, 38, 2005, 6140-6151.

Mitra A, Nath R.K, Biswas S, Chakraborty A.K, Panda A.K, A comparative study on the physico-chemical properties of bacterial capsular polysaccharides from different serotypes of Klebsiella, J. Photochem Photobiol, A. Chemistry, 178, 2006, 98.

Otsuki S, Adachi K, Metachromasy in Polymer Films, Changes in the Absorption Spectrum of Methylene Blue in Nafion Films by Hydration, Polymer Journal, 25, 1993, 1107-1112.

Pal MK, Ghosh BK, Metachromasia of pinacyanol chloride induced by synthetic polyanions, Macromol. Chem., 180, 1979, 959-967.

Pal MK, Ghosh BK, Not all poly anions induce a J-band in the dye pseudo isocyanine, Macromol. Chem., 181, 1980, 1459-1467.

Pal MK, Schubert M, Specific adsorption of metachromatic compounds of Chondroitib sulfate by insoluble calcium salts, J. Histochem. Cytochem, 9, 1961, 673-680.

Ramus J, Alcian Blue: A Quantitative Aqueous Assay for Algal Acid and Sulfated Polysaccharides, Journal of Phycocology, 13, 1977, 345.

Romani A.P, Gehlen M.H and Itri R, Surfactant--polymer aggregates formed by sodium dodecyl sulfate, poly(Nvinyl-2-pyrrolidone), and poly(ethylene glycol), Langmuir, 21 (1), 2005, 127-133.

Rose N.J, Drago R.S, Molecular Addition Compounds of Iodine. I. An Absolute Method for the Spectroscopic Determination of Equilibrium Constants, J. Am. Chem. Soc., 81 (23), 1959, 6138-6141.

Seely G.R, Knots R.R, Binding of methylene blue to alginate: Effect of acid treatment on metachromasy, Carbohydrate Polymers, 3, 1983, 109-127.

Shirai M, Murakami Y, Tanaka M, Interaction between dyes and polyelectrolytes, Metachromatic behavior of methylene blue induced by poly (sodium acrylate) and its homologues, Makromol. Chem., 178, 1977, 2141-2147.

Shirai M, Nagaoka Y, Tanaka M, Interaction between dyes and polyelectrolytes, Effect of organic and inorganic salts on metachromasy of methylene blue, Makromol. Chem., 178, 1977, 1633-1639.

Shirai M, Nagatsuka T, Tanaka M, Interaction between dyes and polyelectrolytes, Metachromatic behavior of methylene blue induced by potassium poly(vinyl sulfate) and its homologs, J. Polym. Sci: Polym. Chem. Ed., 5, 1977, 2083-2095.

Shirai M, Nagatsuka T, Tanaka M, Interaction between dyes and polyelectrolytes, Structural effect of polyanions on the methylene blue binding, Makromol. Chem., 178, 1977, 37-46.

Shirai M, Nagatsuka T, Tanaka M, Interaction between dyes and polyelectrolytes, Effect of polyanions on the mixed dimer formation of cationic dyes, Makromol. Chem., 179, 1978, 173.

Shirai M, Yamashita M, Tanaka M, Interaction between dyes and polyelectrolytes, Effect of polyanions on alkaline fading reaction of methylene blue, Makromol. Chem., 179, 1978, 747-753.

Tan J.S, and Schneider R.L, Dye binding and its relation to polyelectrolyte conformation, J. Phys. Chem., 79, 1975, 1380-1386.

Villeti MA, Borsali R, Crespo JS, Soldi V, Fukada K, Static and Dynamic Light Scattering of Polyelectrolyte/ Surfactant Solutions: the Na-Hyaluronate/(C10TAB) System, Macromol. Chem. Phys., 205, 2004, 907-917. 